\title{
Performed Inclusion Criterion
}

National Cancer Institute

\section{Source}

National Cancer Institute. Performed Inclusion Criterion. NCI Thesaurus. Code C93368.

A characteristic or requirement that a subject must meet to participate in a study. 